\title{
El escozor de la alteridad: un análisis sobre la construcción mediática del migrante colombiano en la televisión chilena
}

\section{The stinging of otherness: An analysis about the Colombian migrant media construction in the Chilean television}

\author{
María Fernanda Stang \\ Programa Interdisciplinario de Estudios Migratorios (PRIEM) \\ Candidata a Doctora en Estudios Sociales de América Latina, Universidad Nacional de Córdoba \\ ferstang@yahoo.com.ar
}

Vanessa Solano Cohen

Universidad Nacional de Córdoba

Doctora en Estudios Sociales de América Latina, Universidad Nacional de Córdoba

vasoco@gmail.com

\begin{abstract}
Resumen
El modo en que una sociedad resignifica la alteridad, a partir de la figura del migrante, permite cuestionar los procesos de construcción de identidad(es) nacional(es) de un determinado país. En este artículo se indaga en los modos en que se construye mediáticamente esa alteridad como amenaza, representada por el migrante colombiano, para poder comprender, desde la configuración discursiva del Otro, algunos procesos caracteristicos de la formación nacional de alteridad en el Chile actual. Para cumplir este objetivo se han seleccionado tres tipos de formatos de lenguaje audiovisual televisivo, que tematizan y figurativizan al migrante colombiano: un reportaje, un stage en un programa de humor y una telenovela, transmitidos por televisión abierta desde julio del 2012 hasta febrero de 2017, abordados desde un análisis sociosemiótico del discurso.

Palabras clave: migración colombiana, Chile, construcción mediática, alteridad, identidad(es) nacional(es).

Abstract

The way in which a society redefines the otherness, based on the figure of the migrant, makes it possible to question the processes of the national identity(ies) construction of a country. This article explores the ways in which this otherness is constructed as a threat, represented by the Colombian migrant, we want to understand, from the Other discursive configuration, the characteristic processes of the otherness national formation in present-day Chile. In order to achieve the objective, three types of audiovisual language formats have been selected, which are thematically and figuratively portrayed to the Colombian migrant: a report, a stage in a humor program and a soap opera, broadcast on television from July 2012 to February 2017, addressed from a socioemiotic discourse analysis.
\end{abstract}

Keywords: Colombian migration, Chile, Media construction, otherness, national identity(ies).

\section{Cronotopías de una amenaza ${ }^{1}$}

Así como en una dimensión jurídico-política, el migrante cuestiona el Estado, fundamentalmente en su rol de garante de derechos - en la medida en que esa tutela solo se ofrece a aquellos que son considerados ciudadanos de ese Estado (Agamben, 1998)-, en una dimensión sociocultural, el migrante pone en tensión la configuración cultural nacional (Grim-

1 Este apartado constituye un avance del trabajo de tesis que se encuentra desarrollando Fernanda Stang para optar al título de Doctora en Estudios Sociales de América Latina, de la Universidad Nacional de Córdoba, Argentina. El proyecto de tesis se titula "Migración y homosexualidad, la arbitrariedad de las fronteras". 
son, 2012) a la que arriba, puesto que expone los antagonismos que atraviesan esa sociedad de destino (Tijoux y Palominos, 2016). Esa presencia, en su no pertenencia, interpela a esa configuración cultural a problematizar sus formas de construcción de alteridad -base de esos antagonismos- y, de ese modo, a interrogarse por la identidad que en esa definición del Otro se construye. Analizar el discurso televisivo como una expresión de las reacciones de una parte importante de la sociedad chilena ${ }^{2}$ ante el crecimiento significativo de cierto tipo de migración en los últimos años es, por lo tanto, un camino posible para preguntarse sobre estos antagonismos y, en especial, sobre las jerarquías que esta construcción de alteridades genera, y las formas de discriminación que habilita.

La población migrante internacional ha crecido de manera notoria en el último cuarto de siglo en Chile, y sobre todo en el último quinquenio. Según una de las estimaciones oficiales más recientes, en 2014 residían en el país 410.988 inmigrantes, lo que representaría un 2,3\% de la población nacional (DEM, 2016) ${ }^{3}$. La Encuesta de Caracterización Socioeconómica (CASEN) de 2015 registró 465.319 inmigrantes (2,7\% de la población nacional) (MDS, $2016)^{4}$. Si se consideran los datos del censo nacional de 2002, la representación de la población migrante internacional se habría prácticamente duplicado en 12 años (del 1,2\% al 2,3\%), lo que ha supuesto que Chile se transforme en un país de inmigración en términos netos (Thayer y Durán, 2015). De todos modos, esta sigue siendo menor que la que registran los principales países receptores de la región como Argentina, donde la población migrante representaba en 2010 el 4,5\% (Martínez et al., 2014), y está muy lejos del promedio en los llamados "países desarrollados", con una representación del 11,3\% por la misma fecha (Rojas y Silva, 2016).

Ahora bien, más allá de que su peso en la población nacional no sea muy significativo, su crecimiento, como decimos, ha sido notable desde la década de
1990. Entre el censo de 1992 y el de 2002, la población migrante de Chile creció un $76 \%$, cuando en la década anterior lo había hecho solo en un 25\%. Si se considera la estimación más reciente del Departamento de Extranjería y Migración (DEM) y el Instituto Nacional de Estadística (INE), el incremento de la población inmigrante entre 2005 y 2014 habría sido del 193\%; aunque también es cierto que las cifras que se barajan desconocen la migración irregular, que incrementaría el número. Aun así, el peso proporcional sobre el total de la población es tan bajo que en principio podría resultar difícil entender de dónde surgen las imágenes asociadas a la "oleada migratoria" o la "invasión de migrantes" que se construye en cierto sector de la prensa nacional $-y$ del espectro político-, y que tiene indiscutibles implicancias en la percepción general de la sociedad. Una imagen que por lo demás no es novedosa, y que se agitó también entre actores semejantes en la década de 1990 y principios de la de 2000, pero en relación con la llegada de otros inmigrantes, peruanos principalmente (Doña, 2002). El hecho de que esta población migrante esté concentrada territorialmente, sobre todo en la Región Metropolitana, donde residía el 61,5\% en 2014 (DEM, 2016), y especialmente en algunas comunas ${ }^{5}$, abona estas metáforas. Pero nuestra principal hipótesis es que estas construcciones imaginarias se tornan legibles a la luz de lo que podemos considerar las principales características de la formación nacional de alteridades (Segato, 2007) propia de Chile; y es esa mirada analítica la que consideramos que permite contextualizar la construcción del migrante colombiano que prima en el discurso televisivo que analizamos en este artículo ${ }^{6}$.

Con la idea de formaciones nacionales de alteridad, Rita Segato pretende llamar la atención sobre el hecho de que "los procesos de otrificación, racialización y etnitización propios de la construcción de los estados nacionales emanan de una historia que transcurre dentro de los confines, y al mismo

2 Importante en relación con su posición en las relaciones de poder, y a su capacidad de incidencia, no necesariamente por su representación cuantitativa.

3 Esta constituye una cifra aproximada, debido a los problemas que tuvo el censo nacional de 2012, que han obligado a valerse de estimaciones de diverso tipo hasta que se cuente con los resultados del censo abreviado aplicado en 2017. En ese marco, este dato del DEM es uno de los más confiables, en la medida que se sustenta en una estimación que toma como base la información de permisos otorgados por esa institución, y proyecciones de población del INE.

4 Hay que advertir, de todos modos, que una encuesta no es un instrumento del todo apropiado para medir la población migrante internacional.

5 Según cálculos propios sobre la base de datos de la encuesta CASEN de 2013, Thayer et al. (2016) estimaron que la tasa migratoria de la comuna de Independencia era de 17,3 migrantes por cada 100 habitantes, y la de Santiago de 16,5.

6 Es importante tener en cuenta que en nuestro análisis estamos considerando canales de televisión de aire de alcance nacional, puesto que los medios regionales pueden tener elementos de caracterización especificos muy notorios. 
tiempo plasma el paisaje geográfico y humano de cada país" (2007: 28); es decir, cada formación nacional, "en tanto matriz idiosincrática de producción y organización de la alteridad interior de la nación", presenta formas de racismo, prejuicios y discriminación étnica que son específicos de ese orden particular, construidas en una historia propia. Por lo tanto, aunque claramente las construcciones de alteridad de la sociedad chilena tienen elementos comunes a una historia colonial y colonialista latinoamericana, también presentan particularidades que es necesario considerar si se pretende entender el lugar en el que es inscrito el migrante colombiano por estos días, y que, por supuesto, es alimentado por determinadas imágenes de la "colombianidad" que circulan globalmente -que mencionaremos más adelante-, pero que son reapropiadas de un modo específico en el contexto de esta formación nacional de alteridad.

No es casual entonces que estas imágenes de "masividad", "oleada" e "invasión" estuvieran asociadas primero, sobre todo, a los inmigrantes peruanos -vinculados a la población indígena andina (Rojas y Silva, 2016)-, y actualmente a ciertos migrantes colombianos especialmente, además de dominicanos y, más recientemente, haitianos ${ }^{7}$, todos ligados por sus marcas de afrodescendencia -porque el colombiano al que se alude no es precisamente el blanco, de clase media y profesional, que también ha llegado al país, evidenciando claramente, además, un proceso de racialización de las relaciones de clase $^{8}$ (Margulis, 1999)-. No es que no exista una correspondencia con un aumento efectivo de estos grupos nacionales -muy alejado por cierto de una masividad-: en el caso de los migrantes colombianos en particular, que es el que interesa en este artículo, el crecimiento fue de un 394\% entre 2005 y 2014 (DEM e INE, 2016), el más alto entre los diez grupos de migrantes con mayor representación en el país por 2014, pasando de 5.066 a 25.038 personas. Lo que resulta diciente, sin embargo, es que esas imágenes no estuvieran relacionadas con otros "colectivos" que también experimentaron crecimientos en este momento o en otros, como los argentinos ${ }^{9}$.

Una mirada a la normativa migratoria chilena, como una de las cristalizaciones de esta formación nacional de alteridades, provee algunos elementos explicativos a nuestras inquietudes. La primera norma (y política) orientada a regular la migración internacional en Chile, según la exhaustiva revisión de Cano, Soffia y Martínez (2009), revela un propósito estatal de atracción de inmigrantes europeos con fines eugenésicos: se trata de la Ley de Colonización de 1845. El proyecto inmigratorio que está en la base de esta norma tenía dos propósitos fundamentales: poblar las tierras "deshabitadas" y "mejorar la raza chilena". Esta ley establecía los países europeos de origen de los inmigrantes que vendrían a conformar las colonias: "Las primeras regulaciones dejan entrever el alto estatus conferido a los inmigrantes de origen europeo -por su 'talante laborioso' y sus rasgos caucásicos- y un contrapuesto rechazo hacia los de países árabes y asiáticos" (Cano et al., 2009:48). Detrás de esta construcción de alteridades deseables e indeseables está la constitución del Estado-nación chileno sobre la base de un orden colonial, que fue a su vez un orden racial -orden que suponía un capital racial positivo para el blanco y negativo para el no blanco (indio y negro principalmente) (Segato, 2007)-. Las categorías raciales heredadas de ese orden colonial, a partir de las que se construyó el Estado-nación en Chile, representaron un elemento decisivo "tanto

7 Decimos recientemente porque en principio hubo una construcción paternalista del migrante haitiano, ligada a la idea que se trata del país más pobre de América Latina, azotado por desastres naturales (el terremoto de 2010), y a que el haitiano es "más sumiso", "más ordenado", "más humilde" que el colombiano. Sin embargo, en el último tiempo se puede percibir una transformación de esta imagen, probablemente asociada a un incremento más notorio aún de su presencia (Rojas y Silva, 2016). Esto ejemplifica además el carácter dinámico de estas construcciones de alteridad. Algo semejante ocurrió con los migrantes peruanos, sobre todo hacia el final de la década de 1990 y principios de la del 2000, cuando eran el principal objeto de los procesos de racialización. A modo de ejemplo, por esos años una de las autoras de este artículo escuchó de boca de un humorista callejero de los que se suben habitualmente a contar chistes en los medios de transporte colectivo, que en Santiago había tantos peruanos que en la Plaza de Armas en el centro cívico de la ciudad hasta las palomas eran "negras y chicas [de baja estatura]". Como sostiene Wallerstein explicando los modos en que opera el racismo: "Ciertos grupos pueden desplazarse en la clasificación; algunos pueden desaparecer o unirse entre sí, y otros se desgajan mientras nacen nuevos grupos. Pero entre ellos siempre hay algunos individuos que son 'negros'. Si no hay negros, o si su número es excesivamente reducido, pueden inventarse "negros blancos'" (1988: 57).

8 Con esta idea el autor se refiere al hecho que "las relaciones de clase se han ido conformando históricamente en América Latina... relegando a posiciones de inferioridad y subordinación a la población nativa y, más tarde, con el mestizaje y la incorporación forzada de mano de obra de origen africano, también a la compleja mezcla integrada por las combinaciones entre estos grupos, cuya principal condición de identidad se basaba en no ser blancos" (Margulis, 1999:47).

9 Por ejemplo, la población argentina residente en Chile creció un 140\% entre el censo de 1992 y el de 2002 (base de datos IMILA del CELADE-CEPAL). 
para definir simbólicamente a la nación como para afirmar la distinción entre clases sociales y posiciones de poder" (Tijoux, 2013)

Es posible rastrear la operación de este orden colonial-racial respecto del inmigrante hasta nuestros días. En un trabajo reciente en el que se explora la autoimagen de los chilenos residentes en la Región Metropolitana respecto de los inmigrantes peruanos, ecuatorianos y argentinos, Thayer et al. (2013) encontraron una idea de "raza chilena" construida a partir de una matriz indígena original diluida por la "sangre española", que terminó siendo dominante, y que a su vez se habría blanqueado por la influencia de los flujos migratorios europeos llegados en el siglo XIX y principios del XX: "Sobre esta concepción racializada de sí misma es que la población metropolitana asume que la inmigración andina representa involución racial que devuelve a Chile el componente indígena, antes atenuado por la influencia de la inmigración europea (...) En este sentido, la población nativa busca consolidar la distancia con la inmigración andina y acortarla con la inmigración argentina, portadora del elemento europeo" (Thayer et al., 2013:171).

En su análisis de la construcción del migrante en la prensa nacional durante la década de 1990, Doña (2002) también releva esta oposición entre xenofilia (respecto del migrante europeo, especialmente el alemán) y xenofobia (respecto del migrante reciente, peruano principalmente). La antinomia se hace particularmente evidente cuando a comienzos de esa década, durante la crisis de los países de Europa del Este, empieza a hablarse de la posibilidad de fomentar una inmigración selectiva de científicos, profesionales y técnicos eslavos, una posibilidad que se liga a la imagen del colono alemán de antaño (Doña, 2002). Esta iniciativa coincide con la presentación de un proyecto de ley sobre migraciones ( $N^{\circ}$ 2.891) en noviembre de 1993, durante la gestión de Patricio Aylwin (1990-1994). El proyecto fue archivado en julio de 1997, pero su texto revela el pensamiento de Estado de esos años en torno a la migración, y especialmente, el hilo de continuidad de esta matriz de construcciones de alteridades de la sociedad chilena. El texto está profusamente marcado por la idea de una política migratoria selectiva, tanto desde las necesidades de desarrollo del país como desde la potencial incidencia de la llegada de migrantes en la sociedad: en el proyecto se consideran "aspectos como la necesidad de una normal y progresiva inserción programada y congruente con los objetivos trazados al incorporar extranjeros, a fin de evitar el riesgo de que en el mediano y largo plazo, se tengan colonias cerradas o con bajo interés de asimilación a la nación chilena" (Stang, 2016, énfasis propio).

El proceso de blanqueamiento de la población chilena fue alimentado durante el siglo XX por una negrofobia exotista presente en el discurso de intelectuales nacionales de diversa procedencia ideológica (Pavez Ojeda, 2016). Jorge Pavez rastrea en esta línea un proyecto de ley, propuesto en 1906 por el diputado del Partido Demócrata por Concepción y Talcahuano, Malaquías Concha, para impedir el ingreso de cierto tipo de migración. El artículo único del texto del proyecto, según lo cita el autor, sostenía que: "[q]ueda prohibida la inmigración en el país de individuos de las razas amarilla o mongólica y de la raza negra o etiópica" (2016:230-231). La iniciativa legislativa puede leerse, entre otras cosas, como una reacción a la llegada espontánea de migrantes a trabajar en las guaneras o salitreras del norte del país, sobre todo asiáticos, principalmente chinos, y también de los países limítrofes (Stefoni, 2011). En su trabajo sobre la prensa nacional en los años noventa, Doña vuelve a relevar lo que pareciera ser "una actitud de hostilidad relativamente generalizada en contra de los asiáticos en Chile" (2002:80), al hilo de un episodio que según su análisis implica el comienzo de la discusión sobre el racismo en el país: se trata de la prohibición de ingresar a una piscina a una mujer coreana, debido "al mal olor que tendrían [los coreanos]". El olor de la piel constituye una poderosísima operación metonímica del racismo chileno. La alusión a los olores de ciertos migrantes - generalmente asociado a sus comidas típicas- ha aparecido profusamente en estudios realizados en los últimos años, especialmente en el escenario escolar ${ }^{10}$, y generalmente respecto de los niños peruanos y haitianos (por ejemplo, Tijoux, 2013; Riedemann y Stefoni, 2015; Stefoni et al., 2016; Stang y Stefoni, 2016).

Aunque el proyecto de Malaquías Concha no prosperó, es indicativo de esta línea de pensamiento eugenésica, que aparecerá coagulada nuevamente en el Decreto con Fuerza de Ley No 69, la segunda

10 Rolando Poblete y Caterine Galaz (2007) investigaron, en el contexto escolar, la construcción de la identidad chilena, a partir de procesos de cristalización de una imagen de uniformidad social, que se reproduce en los discursos hegemónicos y que posibilita marginar la otredad, entendida como subalterna y al margen de la normalidad homogénea del "ser chileno". Los investigadores señalan que el migrante condensa una imagen de subalternidad y alteridad, que se reproduce en la escuela y por ende en las relaciones interpersonales. 
normativa oficial de inmigración, promulgada en 1953, que creó el Departamento de Inmigración, encargado de administrar los flujos migratorios. En los considerandos que fundamentan la norma se alude a la necesidad de un efectivo plan inmigratorio por razones demográficas, étnicas y económicas, y a que "la inmigración con elementos de selección contribuirá a perfeccionar las condiciones biológicas de la raza". Al establecerse las funciones del Departamento, en el artículo $3^{\circ}$, se detalla que una de ellas será: "Proponer todas las iniciativas que convenga adoptar en lo relativo a una política de inmigración que incremente la capacidad productora y técnica del país y que mantenga y asegure la unidad espiritual de la nación, mediante la incorporación de elementos aptos y fácilmente asimilables, evitando el ingreso de individuos indeseables o inadaptables" (énfasis propios).

Esta política migratoria, tempranamente asociada a un trasfondo eugenésico relacionado con ese orden colonial-racial, tuvo continuidad con la normativa elaborada durante la dictadura del General Pinochet, que construyó al migrante como una amenaza contra el orden interno de una nación imaginada como un pueblo homogéneo y unitario, imagen en la que el discurso militar desempeñó un rol significativo, sobre todo en un momento en el que el lugar enunciador del general del ejército coincidió con el del mandatario-dictador (Cuevas, 2014). En el texto de esta normativa, que sigue vigente hasta la actualidad, la amenaza es ideológica: en el inciso primero del artículo 15, se prohíbe el ingreso al país de "[l]os que propaguen o fomenten de palabra o por escrito o por cualquier otro medio, doctrinas que tiendan a destruir o alterar por la violencia, el orden social del país o su sistema de gobierno, los que estén sindicados o tengan reputación de ser agitadores o activistas de tales doctrinas y, en general, los que ejecuten hechos que las leyes chilenas califiquen de delito contra la seguridad exterior, la soberanía nacional, la seguridad interior o el orden público del país y los que realicen actos contrarios a los intereses de Chile o constituyan un peligro para el Estado". Hay que recordar que el telón de fondo que explica el surgimiento de este decreto-ley es la Doctrina de la Seguridad Nacional, es decir, un contexto de Guerra Fría, y el derrocamiento violento de un gobierno (el de la Unidad Popular) que significó para este imaginario un concreto avance del enemigo comunista sobre América Latina. Se trata por lo tanto de un enemigo que es ubicuo, que puede colarse por las fronteras, que necesitan ser fortalecidas. La eugenesia es ahora, además, ideológica.
En un sugerente análisis sobre la normativa y la política migratoria chilena en perspectiva histórica, desde la ley de 1845 hasta el anterior gobierno de Michelle Bachelet (2006-2010), Stefoni (2011) encuentra un hilo conductor de esta historia en la construcción del migrante como una amenaza. Según su propuesta de lectura, en el período marcado por la ley de colonización, la amenaza estaba representada por ese migrante indeseable que llegaba en forma espontánea, por fuera de la política colonizadora conducida por el Estado; durante la dictadura, el migrante se concibió como una amenaza ideológica al orden interno, y en los gobiernos posteriores se lo ha construido como amenaza en tanto problema social, asociado a la pobreza y la delincuencia: "Lo interesante es que en todas estas narrativas encontramos un punto en común, la del extranjero cuya sola presencia constituye una amenaza para el orden social, representación que encuentra terreno fértil en la reproducción de estructuras de discriminación y exclusión" (Stefoni, 2011:82). Esta línea argumental es consistente también con la propuesta que sostiene que la normativa migratoria chilena desde 1975 hasta la actualidad se ha estructurado en torno a la noción de seguridad, idea que de todos modos se ha ido reconfigurando en su persistencia (Stang, 2016).

La amenaza "racial", en tanto, es decir, la amenaza contra la blanqueada "raza chilena", aunque ya no está presente de manera explícita en el texto de la normativa migratoria (en rigor, de extranjería) vigente, sigue operando en numerosos mecanismos no formales a partir de los que la política migratoria funciona. En varios estudios recientes (Liberona, 2015; Stang y Stefoni, 2016; Rojas y Silva, 2016) se han relevado testimonios que dan cuenta de que ciertos resquicios arbitrarios de los que se dispone para el control fronterizo - a cargo de la Policía de Investigaciones- operan obstaculizando principalmente el ingreso de la población afrodescendiente. En efecto, Rojas y Silva (2016) analizan en su trabajo la tasa de rechazo a nivel nacional, entre 2008 y 2015, es decir, los reembarcados según el total de extranjeros que solicitan el ingreso en frontera. Ese análisis muestra que los valores más altos los presentan aquellos grupos nacionales con mayor proporción de población afrodescendiente: dominicanos, haitianos y colombianos. En los tres casos se observaron crecimientos notables de la tasa de rechazo entre 2010 y 2014. Los haitianos y los dominicanos presentaron su tasa de rechazo más elevada en 2012, con el 53,3\% y el 19,8\% del total de las solicitudes de ingreso en frontera rechazadas, 
respectivamente. Fue ese año justamente que se impusieron dos requisitos extra de ingreso para las personas de estos orígenes: carta de invitación para los haitianos y visa consular para los dominicanos. Los colombianos, por su parte, registraron su nivel más alto de rechazo en 2013, con el 7,8\%.

Un último elemento que tiene un alto valor explicativo para entender los procesos de construcción del Otro en la formación nacional de alteridades de la sociedad chilena es lo que Thayer et al. (2013) llaman la geo-identidad, que también identifican como un referente de diferenciación transversal de la población chilena metropolitana frente a los migrantes. Se trata del rol significativo que se confiere a la condición geográfica del país como influencia sobre la conformación de una singularidad nacional: la del "país isla". Según esta imagen, el país tendría ciertas fronteras naturales que habrían contribuido a una posición de aislamiento del mundo: desierto por el norte, cordillera por el este, mar por el oeste y el sur, esto sumado además a su posición como país más austral del mundo. "El aislamiento -sostienen Thayer et al. a partir de sus hallazgoshabría funcionado como un factor de inmunización frente a la influencia desestabilizadora de los países latinoamericanos. Esta protección geográfica estaría actualmente siendo vulnerada por la llegada de migrantes, que serían potenciales importadores de hábitos y prácticas que reproducen esos males" (2013:175). En la medida que la identidad se construye en torno a un sustrato geográfico protegido, la llegada del Otro no puede leerse sino como invasión y amenaza.

Estos elementos, que en buena medida definen la formación nacional de alteridad de Chile, proveen herramientas argumentales importantes para entender el modo en que el migrante colombiano está siendo construido por el discurso televisivo chileno metropolitano en la actualidad. Hay otros factores para considerar, por supuesto, que se relacionan más bien con ciertas representaciones mediáticas globalizadas respecto de la colombianidad, que provienen del país de origen. Pero en lo que al país de destino corresponde, y solo a modo de hipótesis abierta, podría también pensarse que, en la medida que "[l]as diferencias con los otros se representan de manera exagerada en ciertas coyunturas históricas para acentuar la identidad propia o la unidad nacional" (Cuevas, 2014:494), ciertas construccio- nes hiperbólicas respecto del migrante colombiano, elaboradas en un proceso de alterización como Otro naturalmente violento hasta la brutalidad, Otro racialmente distante, bullicioso, fiestero, sexualizado más allá de lo moralmente admisible, ajeno a ordenamientos y controles institucionales, constituyen una reacción exagerada ante la inestabilidad que genera la corrosión de otro pilar identitario poderoso para el chileno: la fortaleza institucional. Esta idea, asociada sobre todo a "la probidad de las policías y autoridades políticas, y a la estabilidad de las instituciones de gobierno" (Thayer et al., 2013:173), estaría siendo amenazada en el contexto actual por la emergencia de casos de corrupción política, empresarial y de las fuerzas de seguridad ${ }^{11}$ que desmentirían el muy sólido mito según el cual "en Chile las instituciones funcionan", que ha operado como un rasgo identitario poderoso.

\section{Notas metodológicas: la hegemonía discursiva como herramienta de lectura}

Este artículo se sitúa metodológicamente desde una perspectiva sociosemiótica, recurriendo al análisis del discurso a partir de la teoría sobre los discursos sociales de Marc Angenot (2012). Para el autor, los discursos constituyen hechos sociales y lugares de producción del sentido: "El discurso social es todo lo que se dice y se escribe en un estado de sociedad, todo lo que se imprime, todo lo que se habla públicamente o se representa hoy en los medios electrónicos. Todo lo que se narra y argumenta, si se considera que narrar y argumentar son los dos grandes modos de la puesta en discurso" (Angenot, 2012:21).

El carácter compuesto del discurso social, en el que operan tendencias hegemónicas, entendidas como reglas prescriptivas que clasifican lo narrable y argumentable, permite leer los modos en los que la hegemonía discursiva produce a la sociedad, estableciendo un orden de lo decible que tiende a la homogenización discursiva. En términos metodológicos, esto significa, en primer lugar, identificar las regularidades de ese gobierno sociodiscursivo (sistemas, topos, temas, enunciados, formas de argumentación y narración), que a su vez condicionan la división social del discurso; y en segundo lugar, indagar en la relación con la doxa, es decir, con "el común denominador social y (...) el repertorio tó-

11 Nos referimos a bullados casos de corrupción como Penta, Caval, Milicogate, Pacogate, colusión del papel higiénico, colusión de las cadenas de farmacia, entre otros, sobre los que pueden encontrarse abundantes referencias en la prensa nacional. 
pico ordinario de un estado de sociedad" (Angenot, 2012:40).

En el siguiente apartado, a partir del análisis del corpus delimitado, queremos identificar los elementos de la hegemonía discursiva que han configurado a la alteridad como amenaza, y que son rastreables en la construcción mediática del colombiano en la televisión abierta chilena metropolitana ${ }^{12}$ en la actualidad. Nos interesa reconocer los topoi ${ }^{13}$, los lugares comunes que (re)producen la opinión sobre la migración de este origen, y analizar cómo la hegemonía discursiva, entendida como norma, configura a partir del lenguaje un egocentrismo/etnocentrismo que valida y legitima una determinada construcción mediática de la alteridad ${ }^{14}$.

Para el análisis de la forma en que se construye al migrante colombiano en la televisión chilena durante los últimos años -entre 2012 y mediados de 2017- hemos seleccionado tres tipos de formato de lenguaje audiovisual: un reportaje (Sicarios de importación, del programa En la mira, Chilevisión, 15 de agosto de 2016), un sketch en un programa de humor (Morandé con Compañía, Mega, 27 de junio de 2015) y una telenovela (La Colombiana, TVN, lanzamiento 1 de marzo de 2017), todos transmitidos por televisión abierta. El corpus está delimitado por un periodo de tiempo que coincide con un incremento del número de visas otorgadas por el Departamento de Extranjería y Migración a este grupo nacional: entre 2012 y 2014 aumentaron en $164 \%$-considerando visas de residencia definitiva, de estudiante y sujetas a contrato- (DEM, 2016). Las piezas audiovisuales fueron seleccionadas principalmente por sus repercusiones, tanto en la audiencia chilena, a partir de las denuncias presentadas ante la Comisión Nacional de Televisión (el reportaje sobre el sicariato y el sketch, que implicaron multas a los dos canales), como en el público colombiano, que derivaron en una intervención de actores diplomáticos (la presentación por parte de la Cancillería colombiana de una queja formal frente a la Comisión Nacional de Televisión por el sketch, y el positivo reconocimiento del embajador de Colombia, Mauricio Echeverry, a la telenovela).

\section{Esta no es mano chilena}

"Han ido insertando sus crueles costumbres en nuestras poblaciones", la voz de la presentadora sitúa al comienzo del programa el eje oposicional que, de manera subrepticia, atraviesa todo el reportaje que está presentando: un nosotros/otros que se establece en torno a la crueldad, una violencia brutal que, junto a una primacía de caras y cuerpos negros, cuerpos tatuados y con cicatrices, y una vinculación implícita con la pobreza, constituyen los nudos significantes alrededor de los cuales este fragmento de discurso construye al colombiano. Hablamos del reportaje Sicarios de importación, del programa En la mira, emitido por el canal nacional de aire Chilevisión ${ }^{15}$, que mereció una multa de la Comisión Nacional de Televisión en diciembre de ese mismo año, a instancias de quejas de varias organizaciones de y para migrantes ${ }^{16}$.

La criminalización de la migración, o más bien de cierto tipo de sujetos migrantes, no es un proceso social exclusivo del escenario chileno, ni tampoco, en este escenario puntual, ha tomado solamente al colombiano como objeto; Doña (2002) rastrea este tratamiento en la prensa nacional durante la década de 1990 respecto de otros grupos, entre ellos peruanos. Se trata de un fenómeno global que ha ido tomando diversos rostros en diferentes contextos, y que se vincula con la forma que ha adquirido la relación entre migración y seguridad en las últimas décadas, que por otra parte constituye una nueva forma de racismo (Walters, 2010). Pero en el caso de los colombianos en Chile, esa criminalización se construye con ciertas especificidades que se alimentan, por una parte y como señalamos, de discursos mediáticos globalizados, producidos desde el país de origen -las narco-telenovelas y películas principalmente-, retroalimentados o amplificados

12 Aunque, como hemos señalado, se trata de canales abiertos de alcance nacional, la posición enunciativa es netamente metropolitana.

13 Entendemos topoi desde la definición barthesiana, es decir, como el lugar común-caracterización metafórica del lugar en el que se sitúa un argumento- en el que se encuentran los argumentos y los discursos de cualquier tema; lo que significa que invoca al sentido común de los discursos (Barthes, 1982).

14 En países, como España, con mayor representación de población migrante internacional, se han realizado varias investigaciones sobre la construcción mediática de la alteridad, sobre todo en la designación discursiva, alrededor de la relación entre legalidad e ilegalidad (Bañón. A.M., 2002; Airebe, P. et al., 2003; Sampedro. V., 2004; Casero. A., 2007).

15 Véase [en línea] https://youtu.be/6BPXIwHZc_M y https://youtu.be/libQ5yc2cgk.

16 Los argumentos de la decisión están expresados en el Acta de la sesión ordinaria del Consejo Nacional de Televisión del 5 de diciembre de 2016. Entre las organizaciones que expresaron su repudio al programa se encuentra la Mesa Intercultural de Antofagasta, que reúne a varias organizaciones de y para migrantes. 
desde la plataforma hollywoodense -caracterizando a los personajes "narco" como colombianos mayoritariamente-; y por la otra, de los elementos estructurantes de la formación nacional de alteridades de Chile, que ya describimos. En el encuentro de estas configuraciones de sentidos, se construye un país bárbaro en el que la violencia que ha signado un proceso histórico nacional ${ }^{17}$ se encarnaría en cuerpos, caracteres y comportamientos casi por osmosis, con un determinismo cuasi genético, pero selectivo, puesto que solo se manifiesta, desde la lectura chilena, en (o a partir de) la negritud.

El tema a partir del cual se construye esta criminalización es, como lo expresa el sensacionalismo obvio del título del reportaje, el sicariato, que según se anuncia, habría encontrado en Chile su nuevo mercado. La evidencia para esta afirmación, sin embargo, es pobre: un homicidio por una deuda de drogas en el centro de Santiago, que se apoya con imágenes difusas de cámaras de seguridad de un edificio, y la tendenciosa pero falsa vinculación con el femicidio de una joven que se encontró desmembrada en el río Mapocho ${ }^{18}$. El nombre del programa dentro del que se emite el reportaje (En la mira), claro está, ya anuncia una línea editorial, que en esta emisión en particular adquiere su máxima expresión en los comentarios del periodista-autor cuando está llegando a reunirse con Popeye, alias del exjefe de sicarios de Pablo Escobar ${ }^{19}$. Para evidenciar los riesgos que está asumiendo, comenta que circularán por la ciudad en el vehículo de este personaje que los miembros del cartel contrario quieren asesinar, y odiado por muchos familiares de víctimas de su violento actuar. La entrevista con este personaje es además el motivo con el que se agita en el relato el fantasma del magnicidio, que podría llegar junto con estos sicarios que se importan con la migración que está arribando: "El caldo de cultivo para las mafias es la corrupción", dice Popeye, "y estamos en ese pie en Chile", remata el periodista. La amenaza se dirige de manera fantasmagórica al corazón de la institucionalidad chilena, esa que ha sostenido una viga importante de la identidad nacional.

Emergen en algunos fragmentos del reportaje datos o afirmaciones que intentarían introducir algunos matices imposibles; sin embargo, la propia construcción del relato transforma esos fragmentos en una exculpación forzada. El comienzo del reportaje es el súmmum de esta operación condenada a (o planificada para) el fracaso: una mujer de espaldas, afrodescendiente, curvilínea, baja por una calle en la noche de una ciudad; pantalla en negro con datos en blanco: la cantidad de colombianos que viven actualmente en Chile (25.038 personas). Sonido de fondo: hombres con acento colombiano hablando de "los fierros" (las armas); imagen de cuatro jóvenes afrodescendientes en torno a una mesa cargando armas; pantalla en negro con datos: 94,8\% tiene ocupación conocida; imagen de los jóvenes ajustando el arma con un destornillador; dato: solo el 0,36\% del total de extranjeros en Chile comete algún delito ${ }^{20}$; continúa la imagen de los jóvenes preparando armas; pantalla en negro con la leyenda "esta es la historia de un pequeño porcentaje y no de la mayoría". Se pasa luego a la imagen del periodista y el camarógrafo con un joven con la cara

17 Colombia es un país marcado históricamente, desde la segunda mitad del siglo XX, por la presencia de la violencia como instrumento legitimador de poder (Palacios, 2003). La presencia de un periodo llamado La Violencia (1945-1964) caracterizado por el enfrentamiento armado, y por parte de civiles, entre los partidos políticos tradicionales del país, da inicio, a su vez, al conflicto interno armado que ha marcado los procesos históricos, económicos y sociales de los últimos 60 años en Colombia. Por lo anterior, las manifestaciones de violencia en este país son múltiples y complejas, sobre todo cuando entra en juego la dinámica del narcotráfico (y sus violencias), entendido como signo de problemas sociales más profundos e históricamente arraigados (Solano, 2016). La vigencia del conflicto interno armado colombiano es impensable sin la presencia del tráfico de drogas; y éste último se ha alimentado de la misma marginalidad y exclusión social que ha mantenido el estado bélico desde mediados del siglo XX. Es importante señalar que el narcotráfico en Colombia, como sistema de producción, reconfigura los procesos sociales, económicos y políticos en el país y es el responsable de la aparición de nuevos actores sociales como los sicarios y los paramilitares (Solano, 2016).

18 Muchas de las notas emitidas o publicadas en relación con este crimen alimentaron de manera morbosa las imágenes asociadas a este enunciado de violencia salvaje que caracterizaría al colombiano, que muchas veces se liga al uso de grandes cuchillos, sables y la habilidad para desmembrar cuerpos.

19 John Jairo Velásquez Vásquez, alias Popeye, es un exsicario de Pablo Escobar. Tras 23 años de cárcel por los delitos de narcotráfico, terrorismo y homicidio, sale en libertad condicional a finales del 2014, por haber cumplido tres cuartas partes de su condena y por haber colaborado con la justicia colombiana. Hoy transformado en una especie de celebridad virtual (YouTube, Twitter, Netflix), Popeye vive en Medellin, apoya públicamente el partido político de Álvaro Uribe, Centro Democrático, y principal opositor al Proceso de Paz en Colombia. En agosto del 2017 se anuncia por los medios de comunicación chilenos que el exsicario abrirá un local en Santiago que se llamará "El Cartel" y que venderá poleras con frases de su autoría y el libro que escribió durante su presidio; situación que interpretamos como ejemplo de la fascinación social que adquieren los delincuentes en la contemporaneidad (Derrida, 2002), sujetos que, como señalamos, evidencian la violencia del orden jurídico/social y por ende una amenaza "importada" a la institucionalidad chilena.

20 "El problema no es la cantidad -se afirma en un momento- sino la brutalidad, que los hace atractivos para las portadas". A confesión de partes, relevo de pruebas. 
borrosa, en la noche de Santiago. La imagen la toma un segundo camarógrafo, una suerte de metarrelato que refuerza esta construcción de reportaje de guerra; es "el Garra", y dice que por 100.000 pesos $^{21}$ "le dejan chulo tendido" a una persona, "para que usted lo recoja si quiere, garantizado", "garantizado, muerto", enfatiza el periodista, para precisar el sentido. Casualmente dicen, el escenario de esta toma es el frontis del Palacio de Justicia.

Nos preguntamos, ¿cómo pueden contrarrestar esas cifras y leyendas en blanco sobre un fondo negro el poder icónico de esas armas? ¿Cómo pueden tres minutos de rostros y sonrisas de niños (sin protección de identidad), que habilitan al reportero a hablar de la violencia que muchos migrantes colombianos que llegan a Chile tratan de dejar atrás, contrarrestar media hora de exhibicionismo de armas, cuerpos con cicatrices, cuerpos sin vida tirados en calles, zanjones, ríos, cuerpo rodeado de cuervos, patrullas policiales? ¿Cómo puede la introducción final del testimonio del Jefe del DEM (ahora renunciado), diciendo que la participación que los colombianos tienen en el delito es muy inferior a la que tienen en la población nacional, inmunizar al televidente frente al testimonio de un fiscal que describe el método de asesinato de la "corbata colombiana" -extraer la tráquea y otros órganos a partir de la lengua-, método al que le pone patente extranjera: "esa no es mano chilena"? No parece, de todos modos, que los realizadores pusieran estos elementos en una balanza: el tópico del relato es el sicariato, lo demás son datos complementarios, puestos casi como previendo la demanda: el parche antes de la herida.

La amenaza se termina de construir con dos asociaciones reforzadas por su no tematización: negritud y pobreza. La mayoría de los personajes que aparecen a lo largo del reportaje, vinculados a situaciones de violencia -como sicarios o como víctimas-son afrodescendientes. Es cierto que se trata del componente mayoritario de la población de ese territorio colombiano (zona pacífica), es cierto también que, como en el resto de América Latina, hay allí una racialización de las relaciones de clase, pero en esta construcción por omisión la violencia brutal queda irremediablemente asociada a la negritud; y ambas (violencia y negritud) a la pobreza. El momento del relato que coagula este vínculo implícito ocurre cuando la cámara comienza a alejarse de los niños con los que habla el reportero en el barrio de Cali, estos que lo llevan a llamar a la conciencia del chileno que discrimina a los migrantes colombianos, y sin solución de continuidad se pasa a una imagen de un basural en un campamento de Antofagasta, los cuerpos negros otra vez, circulando por ese "peladero" de polvo y basura, perros con tiña y gatos con ojos infectados. Paso seguido: el reclamo de los vecinos chilenos, por todas las consecuencias de esas tomas de terreno. La sobredeterminación de la amenaza (violencia-negritud-pobreza) se amplifica además ante este reclamo no resuelto, frente a un actor municipal que se presenta como inoperante y des-responsabilizado. La escena se cierra con un mensaje comprensivo en tono paternalista: "Lejos de las diferencias [entre chilenos y migrantes en el campamento], al parecer hace falta entender que ya es un hecho que muchos de los que llegan solo esperan encontrar alguna oportunidad, sin ser víctimas de la extorsión, los secuestros, las amenazas y la muerte, para vivir mejor, vivir en paz". La escena remata con un niño afrodescendiente con la camiseta de la selección chilena, sonriendo; la transparencia de la metáfora excusa de interpretaciones.

\section{Café y malicia}

Esposito afirma que la alteridad se caracteriza por ser lo antagónico de una entidad precedente, "un no-yo: su reverso, su sombra" (Esposito, 2009:153), y por la necesidad de confrontar ese otro en relación con un yo. ¿Qué nos dice de aquello que se construye como (la) identidad nacional chilena esta construcción mediática del migrante colombiano, esta elaboración hegemónica selectiva de este reverso? En este apartado nos interesa analizar en particular el modo en que la representación de esa otredad es significada desde el género y la migración, en la medida en que la mujer inmigrante es construida como símbolo de la cultura diferente (Nash, 2005:125) 22 .

En el marco de la Copa América 2015 que se llevó a cabo en Chile, el programa Morandé con compañía ${ }^{23}$ realizó la noche del 27 de junio un especial de humor sobre cuatro hinchas visitantes al evento deportivo; una especie de concurso de belleza en

21 Aproximadamente 154 dólares estadounidenses, según la cotización oficial del 14 de agosto de 2017.

22 Mary Nash $(2000,2004)$ ha investigado las representaciones culturales de las mujeres migrantes en la prensa española, a mediados de los años noventa. Sus estudios señalan que la denominación de la mujer migrante en España se articula bajo dos ejes: por un lado, el etnocentrismo poscolonial, tanto para hombres como para mujeres, y de otra parte, un argumento androcéntrico del discurso de género.

23 Véase [en línea] http://www.elmostrador.cl/noticias/pais/2015/06/30/colombia-se-queja-por-parodia-en-morande-con-compania-ymega-se-disculpal. 
el que, a partir de lugares comunes, se daba paso a la caracterización de cuatro países: Brasil, Argentina, Colombia y Chile. La comediante Belén Mora fue la encargada de representar a la hincha colombiana, rotulada con el apellido Escobar y envuelta en un vestido con los colores de la bandera de Colombia que resaltaba la exuberancia de sus curvas. La "representante cafetera", con un marcado acento de la región de Antioquia, entró al set ofreciendo café con malicia, haciendo no sólo alusión al café de Colombia, sino a una expresión habitual en Chile para referirse al agregado de un poco de alcohol al café, y además, de manera indirecta, a los cafés con piernas ${ }^{24}$, un rubro en el que desde hace algunos años trabajan también migrantes colombianas y dominicanas.

Al entrar ofreciendo café con malicia, la humorista decide romper un paquete, que simula ser cocaína, y echar un par de cucharadas en la taza. Al fondo, frente a la mirada maliciosa de la humorista, solo se escucha al público riéndose. Al preguntarle el conductor del programa los motivos para que ella, Xiomara Escobar, estuviese en la Copa América, la humorista responde: "¿Por qué otra razón una colombiana vendría a Chile? Pero sabes, yo tengo varias amigas que trabajan en el norte, en Antofalombia, perdón Antofagasta, y bueno pues, ellas me dijeron que apenas yo llegara a Chile me pusiera con un café con piernas y bueno aquí estoy, con mi café con piernas. E incluso me dieron los precios y cómo debo vender el café aquí en Chile: 50 la hora, 30 la media, 15 el momento, y 10 la probadita".

La asociación explícita entre prostitución y migración colombiana, que articula el sketch humorístico, es la caricatura de una mujer/cosa reducida a un cuerpo voluptuoso que ofrece malicia, curvas y que derrocha deseo; una hipersexualización de la colombianidad, vinculada a su vez a procesos de racialización -esa colombianidad que no es blanca- y criminalización. La sospecha, la malicia que se significa en la cocaína que endulza el café y el erotismo que connota un cuerpo que grita "las ansias que tenía de ver una curva", aluden explícitamente al narcotráfico como sello "made in Colombia" y a su impacto biopolítico en los cuerpos femeninos, cincelados, como trofeos-cosas que ostentan deseo y como dispositivos para la movilidad social (Solano, 2016), discurso de cuya construcción se han encargado, sobre todo, las producciones mediáticas colombianas. En el sketch, este imaginario global sobre la colombianidad adquiere una caracterización nacional en la referencia a Antofagasta (la misma que se muestra en el reportaje de Sicarios de importación), como ciudad con una representación significativa de migración de este grupo nacional en Chile, al denominarla Antofalombia: un juego de palabras entre Antofagasta, falopa y Colombia, y que ha empezado a constituirse como tropo para construir discursivamente la migración colombiana ${ }^{25}$.

¿Qué nos está diciendo Xiomara Escobar sobre la construcción de la otredad, desde el género y la migración, y cómo la relación que se teje entre mujer/ migrante posibilita, en la construcción mediática, el vínculo entre hipersexualización y criminalidad? La acción y el efecto de sexualizar a la mujer colombiana, reduciéndola a cuerpo, indisciplinado y no normalizado, que ofrece y se ofrece, acusa un proceso de despojo de su sentido moral, entendido con Esposito (2009), al retomar a Singer, como "indicador de humanidad", y la ubica al margen de lo moralmente admisible, locus en el que es reducida a bios, y por el que es posible criminalizarla. La relación entre hipersexualización/criminalidad obedece, a su vez, a discursos coloniales que posicionan al no blanco (al indio, al mestizo, al negro, al asiático) al margen del orden y en la frontera de la marginalidad; en este caso la transgresión del límite moral denota la exageración (del cuerpo, del deseo, de la cocaína, del consumo), herramienta discursiva que acentúa la identidad nacional chilena como un nosotros opuesto a la hipérbole que se significa en la sospecha.

Dos días después de la transmisión, y por orden de la Cancillería, el embajador de Colombia en Chile presentó una denuncia formal al programa frente a la Comisión Nacional de Televisión por la rutina realizada, al "reforzar generalizaciones irresponsables que exacerban la xenofobia y la discriminación"; la Comisión sancionó al canal, considerando que violaba el artículo $1^{\circ}$ de la Ley $N^{\circ} 18.838$ y vulneraba la dignidad personal de los inmigrantes colombianos residentes en Chile ${ }^{26}$.

24 Los "cafés con piernas" son locales, característicos de Chile, en los que se vende solo a hombres café y otros bebestibles que son servidos por mujeres con muy poca ropa. En muchos casos son la antesala de un comercio sexual informal (en línea, http://ciudadyculturauah. blogspot.cl/2014/09/el-cafe-burdel-la-remolienda-del.html).

25 Antofagasta es la región en la que la presencia de migrantes colombianos tiene la mayor representatividad respecto del total de la población migrante regional (11\%), en comparación con el 6,1\% que alcanzan a nivel nacional según los datos del DEM (2016).

26 Los argumentos de la decisión están expresados en el artículo 3 del Acta del 31 de agosto de 2015, entre los cuales resaltamos la generalización de las mujeres colombianas con la prostitución y el narcotráfico, y de la comisión de actos delictivos como sustento económico. 


\section{La Colombiana, o el amor blanqueado que llega al barrio}

Ya en el año 2011, el canal TVN lanzaba una telenovela titulada Esperanza, sobre una trabajadora de casa particular ("nana", para un lenguaje con genealogía en el régimen de la hacienda), de nacionalidad peruana, que viaja desde Lima a Santiago buscando un mejor porvenir para ella y su familia; en el 2017, el canal vuelve a apostar a la representación de migrantes, pero esta vez el grupo nacional elegido es el colombiano, lanzando así el 1 de marzo de este año la telenovela La Colombiana: el amor llegó al barrio. La teleserie es la historia de Ángela Vicario, una doctora colombiana "de corazón noble y puro" que arriba a Chile con su hijo, para empezar una nueva vida, tras una desilusión amorosa en su país natal. Aunque sea médica, no ha logrado convalidar su título -una alusión a una problemática de la migración con esta calificación bastante presente en la agenda mediática-, por lo que decide trabajar como aseadora en un Centro de Salud, mientras logra desempeñarse en su profesión. Su vida en Chile, en Santiago propiamente, se desarrolla en el barrio Yungay -sector histórico de la capital y además un barrio de concentración de población migrante. Ahí conoce a Pedro, un vecino y tendero, opositor de los inmigrantes que han llegado a residir en el barrio, y a quien, desde el amor, logrará hacer cambiar de opinión sobre los otros residentes, que como una invasión, y en sus propias palabras, "llegan para quedarse". Con el transcurso de los capítulos, y el desarrollo de la fórmula del triángulo amoroso, Ángela logrará no sólo trabajar como profesional en Chile, sino conquistar y "ablandar" el corazón del hombre huraño y reacio a la migración.

En el ir y venir de los dos protagonistas se cruzan las historias de otros residentes del barrio; por ejemplo, la de James (por James Rodríguez, el centrocampista), que puede ser entendido como la cara de la "colombianidad" masculina, un joven mulato que erotiza a todas las mujeres y que se gana la vida como peluquero, especialista en cortes al estilo futbolero.

El argumento y la descripción de los dos personajes colombianos relevantes apuntan a que la telenovela puede ser entendida como un espacio de representación de un ideal de sana convivencia entre culturas, en el que chilenos y colombianos se reconocen mutuamente ${ }^{27}$; por lo tanto, rescatamos la intención editorial que reside en reconfigurar al mi- grante colombiano, usualmente significado desde el narcotráfico, la violencia y la prostitución. Si con el sketch nos preguntábamos sobre la relación entre hipersexualización/criminalidad, lo que nos interesa ahora es comprender cómo media el amor, o mejor aún, el ideal del amor romántico, en la construcción de ese otro que irrumpe.

En la telenovela, el amor actúa como dispositivo que disciplina y normaliza, en términos foucaultianos, al otro que se significa en la mujer colombiana; es decir, el recurso narrativo del amor romántico, patriarcal y heteronormativo permite normalizar a esa madre soltera, que busca una mejor vida en el país, y despojarla de su connotación de amenaza. El disciplinamiento y normalización implican a su vez un gesto de victimización; el uso recurrente en los libretos del diminutivo -más allá del uso discursivo nacional como expresión lingüística cariñosa- para referirse ya sea a la protagonista o a su hijo aluden a un estado de marginalidad que el amor neutraliza, y a una jerarquización de género, raza, clase y nación -que se corresponde a una ideología sexista, racista, clasista y nacionalista- que dan cuenta de una inclusión social sustentada en la visión de ese otro (mujer, mestiza, colombiana y de clase popular) como un inferior.

A la mujer/mestiza/colombiana se opone el hombre/ blanco/chileno, y en el juego espectral, que además se maximiza enunciándolo desde lo erótico, se reconoce la jerarquía racial, genérica y nacional; así como el blanqueamiento, o mejor aún, la chilenización como necesidad para la sana y natural integración social. Por otro lado, en el personaje de James, el joven mulato, es posible leer procesos de producción discursiva de su identidad racial, no solo en su trabajo como peluquero, sino en los modos en los que él, como mulato caribeño/colombiano, se relaciona con la mujer blanca/chilena, y que se reducen a su rol de macho, hipersexuado, hiperdotado, que ama el fútbol y las mujeres, topos que son recurrentes en la construcción social de lo masculino.

Al miedo que connota el otro se relaciona de modo ambivalente el amor, una relación de opuestos entre rechazo y aceptación, inclusión y exclusión, que dan cuenta de dos polos que construyen mediáticamente la otredad, dos caras de una ideología sobre la identidad chilena que se significa en el escozor frente a la alteridad, y que nos invitan a reflexionar, retomando las palabras de Eliseo Verón (2004)

27 El 12 de abril del 2017, el embajador de Colombia, Mauricio Echeverry, asiste al matinal Muy Buenos Días del canal TVN, en compañía de su par del Perú, Jorge Luis Valdez, para entregar un reconocimiento por parte de la Embajada colombiana al trabajo realizado por la producción, al promover la convivencia pacífica entre los migrantes y los ciudadanos chilenos. 
sobre el rol de los medios de comunicación en la producción de lo real y sobre la representación de los migrantes en esa gran "democracia audiovisual".

\section{Consideraciones finales}

Algunos de los elementos constitutivos de aquello que describimos, siguiendo a Segato, como la formación nacional de alteridad de Chile, permiten echar luz sobre cierta genealogía de la construcción de la amenaza específica que representa el migrante colombiano actualmente, según lo produce el discurso televisivo. Pero esta dimensión localizada del proceso no debe hacernos perder de vista la mirada estructural que lo explica. En este sentido, el análisis propuesto nos permite además reflexionar sobre el rol que juegan los medios masivos de comunicación en el actual régimen global de gestión de la circulación (Kalm, 2008), construyendo y resignificando ciertas imágenes de las migraciones y de determinados migrantes que aceitan la desigual distribución del capital de movilidad en el mundo, permitiendo un acceso diferenciado a los espacios a distintos grupos de personas; esto es, distribuyendo a discreción la libertad de movimiento. Este doble régimen de circulación de las personas, dirá Balibar (2005), instala una "colour bar", que ya no separa solamente el norte del sur, sino que atraviesa todas las sociedades, intensificando el racismo y las medidas de seguridad. En ese sentido, la construcción de cierto tipo de migrantes como amenaza, a partir del discurso mediático, legitima su expulsabilidad, pero también su explotación.

Como sostienen Mezzadra y Nielsen (2016), los regímenes de control de las fronteras (en sentido amplio) desempeñan "un papel decisivo en la producción de la fuerza de trabajo como mercancía" (2016:48), en la medida que procuran reducir el excedente de movilidad (Mezzadra, 2012). Y lo hacen, claro está, en la frontera literal (la geopolítica), construyendo coladores (más que muros) de personas, filtros que jerarquizan mediante el desigual y arbitrario reparto de la regularidad -porque, no casualmente, algunos indeseables logran colarse-; pero también lo hacen mediante otras fronteras, simbólicas, que van construyendo gradientes de deseabilidad. Los medios masivos de comunicación, y la televisión en particular, son actores clave de esos otros procesos de fronterización, en los que la palabra migración va acompañada del sustantivo crisis, y por ende de un discurso, carente de futuro, en el que el migrante, como agente de la amenaza, anuncia la caída del orden. "Los noticiarios televisivos, los titulares de los periódicos, los discursos políti- cos y los tuits por Internet, que sirven de puntos focales y válvulas de escape para las ansiedades y los temores de la población en general, rebosan actualmente referencias a la 'crisis migratoria' (...) y presagian el desmoronamiento y la desaparición del modo de vida que conocemos, practicamos y apreciamos" (Bauman, 2016: 9).

En las palabras de Bauman, en el Mediterráneo convertido en la fosa humana más grande del mundo, en el cuerpo de Maribel Pujols -la mujer dominicana que murió de cansancio y frío en noviembre de 2016, al ingresar a Chile por El Hoyo, una ruta que empieza en Colombia y termina en la frontera entre el país austral y Perú-, en la malicia de Xiomara Escobar, en el rostro de los niños sin vida que se matan en Cali y cuya ausencia vital se puede importar a Chile, o en la docilidad de Ángela Vicario, no se escribe el desmoronamiento o desaparición del modo de vida que creemos conocer; se enuncia, por el contrario, la ausencia de vida, la negación de los lazos comunes, un escenario más de la crisis inmunitaria, retomando a Esposito (2003), que se caracteriza en la defensa y en el otro, siempre significado en la amenaza.

\section{Bibliografía}

AGAMBEN, G. (1998). Homo sacer. El poder soberano y la nuda vida. (1 ${ }^{a}$ ed.). España: Pre-textos.

ANGENOT, M. (2012). El discurso social. (1 ${ }^{\mathrm{a}} \mathrm{ed}$.). Argentina: Siglo XXI.

AIERBE, P. et al. (2003). Análisis de prensa 2002. Inmigración, racismo y xenophobia ( $1^{a}$ ed.). España: Tercera Prensa.

BAÑóN, A. M. (2002). Discurso e inmigración. Propuesta para el análisis de un debate social. ( $1^{a}$ ed.). España: Universidad de Murcia.

BARTHES, R. (1982). Investigaciones retóricas I La antigua retórica. (1 ${ }^{a}$ ed.). España: Ediciones Buenos Aires.

BAUMAN, Z. (2016). Extraños llamando a la puerta. (1 ed.). España: Paidós.

CASERO, A. (2007). Inmigración e ilegalidad: la representación mediática del "otro" como problema. Revista de Estudios culturales de la Universitat Jaume I, Cultura, Lenguaje y Representación, 33-47.

CUEVAS, H. (2014). Discurso militar e identidad nacional chilena. Polis, 38,1-26.

DEM (Departamento de Extranjería y Migración) (2016). Migración en Chile 2005 - 2014. Chile: DEM.

DERRIDA, J. (2002). El nombre de pila de Walter Benjamin. (2 ed.). España: Tecnos.

DOÑA, C. (2002). Percepción de la inmigración reciente en Chile a través del análisis de medios de prensa. Tesis para 
optar al título de Sociólogo. Santiago: Universidad de Chile.

ESPOSITO, R. (2003). Inmunitas Protección y negación de la vida. ( $1^{\mathrm{a}}$ ed.). Argentina: Amorrortu Editores.

ESPOSITO, R. (2009). Tercera persona. Política de la vida y filosofía de lo impersonal. ( $1^{a}$ ed.). Argentina: Amorrortu Editores

GRIMSON, A. (2012). Los límites de la cultura. Crítica de las teorías de la identidad. (1 ${ }^{a}$ ed.). Argentina: Siglo XXI.

KALM, S. (2008). Governing Global Migration. Lund: Lund University.

LIBERONA CONCHA, N. (2015, diciembre). La frontera cedazo y el desierto como aliado. Prácticas institucionales racistas en el ingreso a Chile. Polis 42. Recuperado el 6 marzo 2016, de https://polis.revues.org/11308.

MARGULIS, M. (1999). La 'racialización' de las relaciones de clase en Margulis, M., et al., La segregación negada: cultura y discriminación social. ( $1^{\mathrm{a}}$ ed.). Argentina: Biblos, 37-62.

MARTÍNEZ, J.; CANO, M. \& SOFFIA, M. (2014). Tendencias y patrones de la migración latinoamericana y caribeña hacia 2010 y desafíos de agenda. (1 ${ }^{\text {a ed. }}$.). Chile: CEPAL.

MDS (MINISTERIO DE DESARROLLO SOCIAL, CHILE) (2016). CASEN 2015. INMIGRANTES. Sintesis de Resultados. Chile: MDS.

MEZZADRA, S. (2012). Capitalismo, migraciones y luchas sociales. "La mirada de la autonomía". Nueva Sociedad, 237, 159-178.

MEZZADRA, S. NEILSON, B. (2016). La frontera como método. O la multiplicación del trabajo. Buenos Aires: Tinta limón.

NASH, M. (2000) Construcción social de la mujer extranjera en Roque, M.A. (dir.) Mujer y Migración en el Mediterráneo occidental. España: Icaria.

NASH, M. (2004) Mujeres en el mundo, Historia, restos y movimientos. España: Alianza.

NASH, M. (2005). Inmigrantes en nuestro espejo. Inmigración y discurso periodístico en la prensa española. ( $1^{a}$ ed.) España: Icaria.

PALACIOS, M. (2003). Entre la legitimidad y la violencia. Colombia 1875-1994. (2ª ed.). Colombia: Norma.

PAVEZ OJEDA, J. (2016). Racismo de clase y racismo de género: 'mujer chilena', 'mestizo blanquecino' y negra colombiana' en la ideología nacional chilena en Tijoux, M E. (ed.). Racismo en Chile. La piel como marca de la inmigración. ( $1^{\mathrm{a}} \mathrm{ed}$.). Chile: Universitaria.

POBLETE, R. \& GALAZ, C. (2007). La identidad en la encrucijada: migración peruana y educación en el Chile de hoy. Emigra Working Papers, 3. Recuperado el 17 de enero de 2018, de https://ddd.uab.cat/pub/emigrawp/emigrawp_a2007n3/emigrawp_a2007n3pl.pdf
ROJAS, N. \& SILVA, C. (2016). La migración en Chile: Breve reporte y caracterización (Informe OBIMID). ( ${ }^{\text {a }}$ ed.). Santiago: DEM y OBIMID.

SAMPEDRO, V. (2004). Identidades mediáticas e identificaciones mediatizadas. Visibilidad y reconocimiento identitario en los medios de comunicación. Revista CIDOB d'Afers Internacionals, 66, 135-149.

SEGATO, R. (2007). La Nación y sus Otros. Raza, etnicidad y diversidad religiosa en tiempo de Políticas de Identidad. ( $1^{\text {a }}$ ed.). Argentina: Prometeo.

SOLANO, V. (2016). La construcción discursiva de la violencia en la novela colombiana (1994-2011). Tesis para optar al título de Doctor en Estudios Sociales de América Latina. Córdoba: Universidad Nacional de Córdoba.

STANG, M.F. (2016, julio). De la Doctrina de la Seguridad Nacional a la gobernabilidad migratoria: la idea de seguridad en la normativa migratoria chilena, 19752014. Polis, 44. Recuperado el 8 de mayo de 2017, de https://polis.revues.org/11848.

STEFONI, C. (2011). Ley y política migratoria en Chile. La ambivalencia en la comprensión del migrante en Feldman-Bianco, B., et al. (comp.) La construcción social del sujeto migrante en América Latina. Prácticas, representaciones y categorías. Ecuador: FLACSO. Ecuador: Consejo Latinoamericano de Ciencias Sociales, CLACSO. Chile: Universidad Alberto Hurtado.

THAYER, E. \& DURÁN, C. (2015, octubre). Gobierno local y migrantes frente a frente: nudos críticos y políticas para el reconocimiento en Revista del CLAD Reforma y Democracia, 63, 127-162.

THAYER, E.; CÓRDOVA, M G. \& ÁVALOS, B. (2013, diciembre). Los límites del reconocimiento: migrantes latinoamericanos en la Región Metropolitana de Santiago de Chile en Perfiles Latinoamericanos 42, 163-191.

THAYER, L.; DURÁN, C.; DILLA, CH.; STANG, F. \& WLADDIMIRO, C. (2016). Observatorio de Política Migratoria. Boletín $\mathrm{N}^{\circ} 1$. Chile: Universidad de Los Lagos.

TIJOUX, M E. (2013). Las escuelas de la inmigración en la ciudad de Santiago: elementos para una educación contra el racismo en Polis, 35, 287-307.

TIJOUX, M E. \& PALOMINOS, S. (2015, diciembre). Aproximaciones teóricas para el estudio de procesos de racialización y sexualización en los fenómenos migratorios de Chile. Polis, 42. Recuperado el 5 de marzo de 2016, de https://polis.revues.org/11351

VERÓN, E. (2004). Fragmentos de un discurso. (1 ${ }^{\mathrm{a}}$ ed.). España: Gedisa.

WALLERSTEIN, I. (1988). Universalismo, racismo y sexismo, tensiones ideológicas del capitalismo en Wallerstein, I. \& Balibar, E. Raza, nación y clase. (1ª ed.). España: Iepala.

WALTERS, W. (2010). "Migration and Security" en Burguess, J. P. (ed.). The Routledge Handbook of New Security Studies. London: Routledge. 